\title{
Cases of diabetic ketoacidosis as an initial presentation of acromegaly
}

\author{
Udaya M. Kabadi ${ }^{1,2,3 *}$ \\ ${ }^{1}$ Veteran Affairs Medical Center and Broadlawns Medical Center, Des Moines, USA \\ ${ }^{2}$ Des Moines University of Osteopathic Medicine, Des Moines, USA \\ ${ }^{3}$ Adjunct Professor of Medicine and Endocrinology, University of Iowa, USA
}

\begin{abstract}
Diabetic ketoacidosis (DKA) is a complication of diabetes mellitus especially of type 1 variety often requiring hospitalization. Herein we report 2 subjects with Acromegaly who presented with DKA as the initial manifestation. In one subject, total remission from diabetes occurred following successful resection of growth hormone secreting pituitary adenoma localized to pituitary fossa without onset of hypopituitarism. In the other subject, total remission of diabetes ensued only after administration of somatostatin (Sandostatin LAR) once a month for 6 months since a complete resection of pituitary adenoma could not be performed due to suprasellar extension and hypopituitarism requiring treatment persisted after surgery.
\end{abstract}

\section{Introduction}

Diabetic ketoacidosis (DKA) occurs as an acute metabolic derangement in subjects with diabetes Mellitus. The common metabolic abnormalities include markedly increased concentrations of ketone bodies, e.g. beta hydroxybutyrate, acetoacetate and acetone in the circulation with concurrent hyperglycemia. DKA is a serious and potentially life threatening complication. Predisposing factors include new-onset type 1 diabetes, insulin withdrawal and onset of acute illness [1-6]. In this report, we describe 2 subjects who presented DKA as initial manifestation of acromegaly secondary to growth hormone producing pituitary adenomas and total remission following resection in one and surgery followed by treatment with Sandostatin in the other

\section{Case report 1}

A 56-year-old Caucasian man was admitted with recent history of polyuria, polydipsia, nycturia, fatigue, muscle weakness, dizziness etc. for duration of 4 weeks. Subject claimed to have lost $12 \mathrm{lbs}$. during the same period and reported nausea, vomiting, upper abdominal pain and blurred vision for 3 days prior to admission. Subject denied fever, dysuria, cough, and chest pain. His facial appearance raised a suspicion of acromegaly. On further inquiry, subject reported increasing shoe size, backache, decline in libido, intermittent headache but no diplopia or photophobia of one-year duration. He had no history of surgery or allergies and was not being treated with drugs for any disorder. He denied smoking and use of illicit drugs or over the counter supplements. He consumed alcohol, mainly beer on weekends for several years. Family history was essentially unremarkable. Physical examination revealed an alert, oriented adult man in moderate respiratory distress with Kussmaul breathing, temperature, $97.4^{\circ} \mathrm{F}$; respiratory rate, $22 / \mathrm{min}$; pulse, 110/min; blood pressure, $108 / 68 \mathrm{~mm} \mathrm{Hg}$ and body weight, 152 lbs.; coarse facial features including prognathism, frontal bossing, thick nose and comodones. The examination of the subject's driver's license issued about 3 years prior to admission confirmed the facial changes. Lung examination showed normal breath sounds. Heart evaluation showed normal heart sounds with tachycardia without a murmur and neurological assessment was unremarkable including no loss of visual field on confrontation testing. Complete Blood Count was significant for WBC $12.600 / \mathrm{mL}$ with segmented neutrophils $56 \%$. Serum chemistries showed sodium, $145 \mathrm{mM} / \mathrm{L}$ (Normal: 135-146); potassium, $3.7 \mathrm{mM} / \mathrm{L}$ (Normal: 3.5-5.3); chloride, $103 \mathrm{mM} / \mathrm{L}$ (Normal: 98-110); $\mathrm{HCO}_{3}^{-}, 7$ $\mathrm{mM} / \mathrm{L}$ (Normal: 20-31); Anion gap, $35 \mathrm{mM} / \mathrm{L}$ (Normal: 8-16); Serum Urea Nitrogen, $42 \mathrm{mg} / \mathrm{dl}$ (Normal: 7-20); serum creatinine, $2.7 \mathrm{mg} / \mathrm{dl}$ (Normal: 0.6-1.2); random serum glucose, $438 \mathrm{mg} / \mathrm{dl}$ (Normal: 79-139, Diabetes > 200); serum osmolality, $326 \mathrm{mM} / \mathrm{kg}$ (Normal: 275-295); serum beta hydroxybutyrate, $22 \mathrm{mg} / \mathrm{dl}($ Normal $<5)$ and lactic acid, $1.0 \mathrm{mM} / \mathrm{L}$ (Normal <2.5). Arterial blood gases obtained at admission simultaneously with laboratory tests showed $\mathrm{pH}, 7.05 ; \mathrm{PO}_{2}, 98 \mathrm{~mm} \mathrm{Hg}$ and $\mathrm{PCO}_{2} 7 \mathrm{~mm} \mathrm{Hg}$. Urinalysis showed specific gravity, 1024; glycosuria and ketonuria but no other abnormalities. Electrocardiogram showed sinus tachycardia with no other abnormality. Chest x-ray was normal. Serum concentrations of Human Growth Hormone (HGH) and Insulin like Growth Factor 1 (IGF1) were determined because of classical manifestations of acromegaly and were within the normal range (Table 1). Presence of hyperglycemia, elevated serum beta hydroxybutyrate and anion gap metabolic acidosis established the diagnosis of DKA. The subject was promptly administered intravenous fluids and insulin infusion as per the treatment protocol for DKA previously established by the institution. Over the next 96 hours, symptomatology improved following resolution of ketoacidosis. At this time, oral feeding was initiated with subcutaneous insulin administration in basal bolus pattern. CT scan of the brain with special attention to pituitary fossa was performed because of classical facial features of acromegaly and showed pituitary macroadenoma, $15 \mathrm{~mm}$ in diameter with no supra

Correspondence to: Udaya M Kabadi, Veteran Affairs Medical Center and Broadlawns Medical Center, Des Moines, USA, Tel: +1-319-594-8575; E-mail: ukabadi@gmail.com

Received: February 12, 2017; Accepted: March 06, 2017; Published: March 09, 2017 
cellar extension or impingement of the optic chiasm. Subject was discharged with advice to continue insulin therapy in basal bolus pattern and follow up with endocrinology clinic in 2 weeks. Pituitary function testing during hospitalization and at this visit confirmed the diagnoses of acromegaly, uncontrolled diabetes, and partial hypopituitarism. e.g. central hypothyroidism and central hypogonadism (Table 1). Subject underwent elective trans sphenoidal resection of pituitary adenoma within 2 weeks. Repeated MRI examination of brain showed absence of adenoma and normal pituitary remnant. During hospitalization over 3 days, subject was treated with insulin infusion and intravenous administration of dexamethasone $0.5 \mathrm{mg}$ every 6 hours. Subject was discharged on basal bolus insulin therapy and oral dexamethasone 0.75 mg daily. Dexamethasone was discontinued after 3 weeks as ACTH stimulation test showed normal cortisol response. Insulin requirement declined gradually over next 8 weeks and ultimately was discontinued. At 3 months following surgery, serum free T4, TSH, free Testosterone, FSH, LH and Prolactin normalized. Total remission of diabetes occurred with subject requiring no intervention along with preserved pituitary function over the follow up period of 12 months (Table1).

\section{Case report 2}

A 39-year-old Latino man was admitted with recent history of polyuria, polydipsia, nocturia, fatigue, muscle weakness, dizziness etc. for duration of 6 weeks. Subject claimed to have lost 6 lbs. during the same period. He also reported nausea, vomiting, upper abdominal pain and blurred vision for 2 days prior to admission. Subject denied fever, dysuria, cough and chest pain. On further inquiry, he reported that his spouse told him 'his facial features had changed' over last 6 months. He also mentioned increasing shoe size, excessive sweating, backache, decline in libido, intermittent headache but no diplopia or photophobia for about 6 months prior to admission. Subject had no surgery or allergies. Past history included hypertension for 2 years and dyslipidemia for a year being treated with Lisinopril 20 $\mathrm{mg}$ and atorvastatin $20 \mathrm{mg}$ daily respectively. He was a smoker for about 20 years. He denied use of alcohol or illicit drugs or over the counter supplements. Family history was essentially unremarkable. Physical examination revealed an alert, oriented adult man in no respiratory distress. However, Kussmaul breathing was apparent with temperature, $102^{\circ} \mathrm{F}$; respiratory rate, 20/min; pulse, 108/min; blood pressure, $134 / 86 \mathrm{~mm} \mathrm{Hg}$ and body weight, $187 \mathrm{lbs}$.; coarse facial features including prognathism, frontal bossing and waxy skin. Chest was barrel shaped. Lung examination showed normal breath sounds with prolonged expiratory phase but no rales or rhonchi. Heart evaluation showed normal heart sounds with tachycardia without a murmur and neurological assessment was unremarkable including normal visual field on confrontation testing. Complete blood count was normal with $\mathrm{WBC}, 5700 / \mathrm{ml}$ and hemoglobin, 15.8 g. Serum chemistries showed sodium, $142 \mathrm{mM} / \mathrm{l}$ (Normal: 135-146); potassium, $4.1 \mathrm{mM} / 1$ (Normal: 3.5-5.3); chloride, $104 \mathrm{mM} / 1$ (Normal: 98-110); $\mathrm{HCO}_{3}, 16 \mathrm{mM} / \mathrm{l}$ (Normal: 24-31); anion gap, $22 \mathrm{mM}$ / (Normal: 8-16); serum urea nitrogen, $32 \mathrm{mg} / \mathrm{dl}$ (Normal: 7-20); serum creatinine, 1.8 $\mathrm{mg} / \mathrm{dl}$ (Normal: 0.6-1.2); random serum glucose, $365 \mathrm{mg} / \mathrm{dl}$ (Normal: 79-139, Diabetes > 200); serum osmolality, $314 \mathrm{mM} / \mathrm{kg}$ (Normal: 275-295); serum beta hydroxybutyrate, $16 \mathrm{mg} / \mathrm{dl}($ Normal $<5)$ and lactic acid, $0.9 \mathrm{mM} / \mathrm{l}($ Normal $<2.5)$. Arterial blood gases obtained at admission simultaneously showed $\mathrm{pH}, 7.22 ; \mathrm{PO}_{2}, 98 \mathrm{~mm} \mathrm{Hg}$ and $\mathrm{PCO}_{2}$ $24 \mathrm{~mm} \mathrm{Hg}$. Urinalysis revealed specific gravity, 1030; glycosuria and ketonuria. Chest $\mathrm{x}$-ray was normal and electrocardiogram showed sinus tachycardia. Serum concentrations of Human Growth Hormone (HGH) and Insulin like Growth Factor 1 (IGF1) were elevated and other pituitary function tests showed panhypopituitarism with exception of diabetes insipidus (Table2). Presence of hyperglycemia, elevated serum beta hydroxybutyrate and anion gap metabolic acidosis established the diagnosis of DKA. The subject was promptly administered intravenous fluids and insulin infusion as per the treatment protocol for DKA previously established by the institution and IV Dexamethasone $0.5 \mathrm{mg}$ every 6 hours for management of ACTH deficiency. Oral levothyroxine, $25 \mathrm{mcg}$ daily was initiated. Over next 48 hours, symptomatology improved with resolution of ketoacidosis. At this time, oral feeding was initiated with subcutaneous insulin administration in basal bolus pattern. CT scan of the brain with special attention to pituitary fossa showed pituitary macroadenoma, $22 \mathrm{~mm}$ in diameter with suprasellar extension as well as impingement of the optic chiasm. Neurosurgery consultation was obtained. Repeated Laboratory tests for pituitary function showed further elevation of HGH and IGF1 concentrations with persistent panhypopituitarism (Table 2). Trans sphenoidal surgery was promptly performed. Subject was discharged on 4th day after surgery with advice to continue insulin therapy in basal bolus pattern, use oral dexamethasone $0.5 \mathrm{mg}$ twice daily and increase levothyroxine by $25 \mathrm{mcg}$ at interval of 7 days until the daily dose of 100 mcg was attained. During return appointment in endocrinology clinic at 4 weeks, serum levels of both free $\mathrm{T}_{4}$ free testosterone and prolactin were still subnormal and ACTH stimulation test showed subnormal responses at 30 and $60 \mathrm{~min}(<10 \mathrm{ug} / \mathrm{dl})$. Therefore, the daily dose of levothyroxine was further increased to $150 \mathrm{mcg}$, Oral dexamethasone was substituted by hydrocortisone, $20 \mathrm{mg}$ in AM and $10 \mathrm{mg}$ in PM and topical testosterone gel $5 \mathrm{~g}$ daily was initiated. Oral metformin $500 \mathrm{mg}$ daily was started with instructions to increase by $500 \mathrm{mg}$ every 7 days to attain the daily dose of $2000 \mathrm{mg}$ in 3-4 weeks if tolerated. Repeated MRI examination of brain showed remnant of adenoma with suprasellar extension but no more involvement of optic chiasm. Insulin requirement declined gradually over next 8 weeks and ultimately was discontinued. At 3 months following surgery, Hbalc declined to 6.9 $\%$ and serum free T4, TSH and free Testosterone concentrations

Table 1. Laboratory Tests of Pituitary Function in Subject 1.

\begin{tabular}{|c|c|c|c|c|c|}
\hline & Normal range & Pre $\mathrm{Rx} 1$ & Pre $R \times 2$ & Post Rx (6 months) & Post $\operatorname{Rx}(12$ months $)$ \\
\hline HGH (ng/ml) & $0-5$ & 3 & 15 & $<1.0$ & $<1.0$ \\
\hline $\mathrm{IGF} 1(\mathrm{ng} / \mathrm{ml})$ & $45-173$ & 171 & 675 & 147 & 152 \\
\hline Free T4(ug/dl) & $0.89-1.76$ & 0.58 & 0.62 & 1.24 & 1.32 \\
\hline $\mathrm{TSH}(\mathrm{miU} / \mathrm{ml})$ & $0.55-4.78$ & 0.12 & 0.16 & 2.8 & 2.1 \\
\hline Free Testosterone $(\mathrm{ng} / \mathrm{ml})$ & $4.3-30.4$ & 2.4 & 3.3 & 16.8 & 22.6 \\
\hline FSH (miU/ml) & $1.4-18.1$ & 0.9 & 1.0 & 6.5 & 8.9 \\
\hline $\mathrm{LH}(\mathrm{miU} / \mathrm{ml})$ & $1.5-7.3$ & 1.6 & 1.5 & 6.1 & 5.8 \\
\hline Prolactin(ng/ml) & $2.5-29.2$ & 2.2 & 1.9 & 17,4 & 21.6 \\
\hline Cortisol (ug/dl) & $5-25$ & 22 & 18 & 15 & 17 \\
\hline $\mathrm{ACTH}(\mathrm{pg} / \mathrm{ml})$ & $10-60$ & 65 & 54 & 46 & 52 \\
\hline HbA1c (\%) & $4.0-5.6$ & 10.6 & 9.8 & 5.4 & 5.2 \\
\hline
\end{tabular}


Table 2. Laboratory Tests of Pituitary Function in Subject 2.

\begin{tabular}{|c|c|c|c|c|c|}
\hline & Normal range & Pre Rx 1 & Pre $R x 2$ & Post Rx (6 months) & Post Rx (12 months) \\
\hline HGH (ng/ml) & $0-5$ & 8 & 22 & 4.6 & 1.8 \\
\hline IGF1 (ng/ml) & $45-173$ & 338 & 1020 & 172 & 136 \\
\hline Free T4(ug/dl) & $0.89-1.76$ & 0.36 & 0.56 & 1.38 & 1.46 \\
\hline $\mathrm{TSH}(\mathrm{miU} / \mathrm{ml})$ & $0.55-4.78$ & 0.68 & 0.60 & 0.42 & 0.46 \\
\hline Free Testosterone $(\mathrm{ng} / \mathrm{ml})$ & $4.3-30.4$ & 2.8 & 3.2 & 12.8 & 18.8 \\
\hline FSH (miU/ml) & $1.4-18.1$ & 2.6 & 3.4 & 1.6 & 2.2 \\
\hline $\mathrm{LH}(\mathrm{miU} / \mathrm{ml})$ & $1.5-7.3$ & 3.6 & 3.2 & 2.8 & 2.1 \\
\hline Prolactin(ng/ml) & $2.5-29.2$ & 1.6 & 2.5 & 4.9 & 6.3 \\
\hline Cortisol (ug/dl) & $5-25$ & 4.2 & $4^{*}$ & $3^{*}$ & - \\
\hline ACTH $(\mathrm{pg} / \mathrm{ml})$ & $10-60$ & 5.9 & - & - & - \\
\hline HbAlc $(\%)$ & $4.0-5.6$ & 9.8 & 8.8 & 5.2 & 5.4 \\
\hline
\end{tabular}

* subnormal response to ACTH stimulation

normalized. However, HGH and IGF1 levels were still elevated at $6 \mathrm{ng} /$ $\mathrm{dl}$ and $360 \mathrm{pg} / \mathrm{ml}$ respectively. Therefore, subcutaneous administration of short acting Sandostatin 100 ug, three times daily was started and continued for 7 days.IM Sandostatin LAR $20 \mathrm{mg}$ was also administered and continued at interval of 4 weeks. IGF1 normalized and HbAlc declined to $5.2 \%$ by 6 months. Therefore, metformin was discontinued while continuing Sandostatin LAR. HbAlc remained 5.1-5.5\% during the follow up period over 12 months denoting a total remission of diabetes.

\section{Discussion}

DKA is often a presenting manifestation of type 1 diabetes mellitus (T1DM) at the time of diagnosis especially in children and adolescents [1]. Among subjects with prior presence of diabetes, DKA ensues following withdrawal or omission of insulin due to psychological, social or economic reasons [1,2] DKA also occurs in subjects with both type 1 and 2 diabetes due to relative insulin deficiency at the onset of acute illness, e.g. infections, myocardial infarction, congestive heart failure, acute pancreatitis as well as during pregnancy and following steroid therapy [1-6]. Recently, we reported a subject who presented with DKA as the initial manifestation of Cushing Disease caused ACTH secreting pituitary adenoma with total remission of diabetes following trans sphenoidal resection (7).

The case reports described herein document DKA as a unique initial presentation in subjects with acromegaly. The diagnosis of acromegaly secondary to growth hormone secreting pituitary adenoma was established in both subjects during hospitalization for DKA. Moreover, the contribution of acromegaly to onset of DKA was also confirmed by lack of presence of any other precipitating disorder described in the literature [1-6]. Finally, total remission of diabetes following a complete resection pf pituitary adenoma in one and partial resection and adjunctive therapy with Sandostatin LAR in the other further adds credence to the role of acromegaly in this unique initial presentation of DKA. Other interesting finding in these subjects with acromegaly was the suppression of both HGH and IGF1 concentrations during the state of DKK indicating a partial autonomous nature of these adenomas. Lack of suppression of these hormones following rise in plasma glucose during OGTT is diagnostic of presence of acromegaly. The reason for the lack of suppressibility of HGH and IGF1 concentrations during OGTT may be attributed to a smaller rise in plasma glucose whereas severe hyperglycemia may have infused suppression in our subjects with DKA. This observation is similar to Cushing's disease secondary to ACTH secreting pituitary adenoma. In this disorder, serum ACTH and Cortisol levels are not suppressed by administration of a single overnight dose of dexamethasone $1 \mathrm{mg}$ or daily administration of $2 \mathrm{mg}$
( $0.5 \mathrm{mg}$ every 6 hours) for 2 days while higher daily dose, $8 \mathrm{mg}$ or $16 \mathrm{mg}$ promptly induces suppression [7]. Finally, the finding of suppression of HGH and IGF1 concentrations by severe hyperglycemia in acromegaly is not documented in the literature [8-24].

Diabetic ketoacidosis as an initial presentation of acromegaly documented in our subjects has been reported in the literature [8-24]. However, in many of these reports, DKA occurred in subjects with prior diagnosis of acromegaly [9,11-15,23]. Moreover, in a few these subjects as well as those manifesting DKA as initial presentation, the onset of DKA could be attributed to an acute disorder $[8,10,11,13$ $15,20,23,24]$. Finally, long lasting total remission of diabetes not requiring any intervention as noted in our subjects has been rarely documented $[11,13,15,19]$. However, in one of these, the presentation was primarily ' Ketosis' and in the other DKA was described as ' mild'. In contrast, DKA was of moderate to severe nature in our subjects. Thus, the presentation in our patient is distinctly more unique in comparison to the reports in the literature.

\section{References}

1. Yong KW, Moore MP, Lunt H (2014) Medically facilitated discharge of adult diabetic ketoacidosis admissions: precipitants and average length of stay. $N Z$ Med J 127: 8694. [Crossref]

2. Randall L, Begovic J, Hudson M, Smiley D, Peng L, Pitre N et. al. (2011) Recurren Diabetes Ketoacidosis in Inner-City Minority Patients Behavioral, social and psychological factors. Diabetes Care 34: 1891-1896

3. Azoulay E1, Chevret S, Didier J, Barboteu M, Bornstain C, et al. (2001) Infection as a trigger of diabetic ketoacidosis in intensive care-unit patients. Clin Infect Dis 32: 30-35. [Crossref]

4. Inagaki T, Nishii Y, Suzuki N, Suzuki S, Koizumi Y, et al. (2002) Fulminant diabetes mellitus associated with pregnancy: case reports and literature review. Endocr $J 49$ : 319-322.

5. Alavi IA, Sharma BK, Pillay VK (1971) Steroid-induced diabetic ketoacidosis. Am J Med Sci 262: 15-23. [Crossref]

6. Nair S, Yadav D, Pitchumoni CS (2000) Association of diabetic ketoacidosis and acute pancreatitis: observations in 100 consecutive episodes of DKA. Am J Gastroenterol 95: 2795-2800

7. Acharya,R, Kabadi U (2017) Case of diabetic ketoacidosis as an initial presentation of Cushing's syndrome. Endocrinology, Diabetes \& Metabolism Case Reports, 02 2017, EDM160123, 10.1530/EDM-16-0123.

8. Vidal Cortada J, Conget Donlo JI, Navarro Téllez MP, Halperin Rabinovic I, Vilardell Latorre E (1995) Diabetic ketoacidosis as the first manifestation of acromegaly. An Med Interna 12: 76-78.

9. Katz JR, Edwards R, Khan M, Conway GS (1996) Acromegaly presenting with diabetic ketoacidosis. Postgrad Med J 72: 682-683. [Crossref]

10. Szeto CC1, Li KY, Ko GT, Chow CC, Yeung VT, et al. (1997) Acromegaly in a woman presenting with diabetic ketoacidosis and insulin resistance. Int J Clin Pract 51: 476477. [Crossref] 
11. Alvi NS, Kirk JM (1999) Pituitary gigantism causing diabetic ketoacidosis. J Pediatr Endocrinol Metab 12: 907-909. [Crossref]

12. Westphal SA (2000) Concurrent diagnosis of acromegaly and diabetic ketoacidosis Endocr Pract 6: 450-452. [Crossref]

13. Kopff B, Mucha S, Wolffenbuttel BH, Drzewoski J (2001) Diabetic ketoacidosis in a patient with acromegaly. Med Sci Monit 7: 142-147. [Crossref]

14. Ma RC, Chow FC, Chung CC, Liu GC, Chan JC, et al. (2002) Diabetic ketoacidosis in acromegaly: indication for long-term insulin therapy? Int J Clin Pract 56: 157. [Crossref]

15. Erem C, Ersöz HO, Ukinç K, Avunduk AM, Hacihasanoglu A, et al. (2006) Acromegaly presenting with diabetic ketoacidosis, associated with retinitis pigmentos and octreotide-induced bradycardia: a case report and a review of the literature. Endocrine 30: 145-149.

16. Chen YL, Wei CP, Lee CC, Chang TC (2007) Diabetic ketoacidosis in a patient with acromegaly. J Formos Med Assoc 106: 788-791. [Crossref]

17. Lakhotia M, Mathur R, Singh H, Gahlot A, Tiwari V, et al. (2007) Diabetic ketosis as a presenting feature of acromegaly. J Assoc Physicians India 55: 377-378. [Crossref]
18. Ali O, Banerjee S, Kelly DF, Lee PD (2007) Management of type 2 diabetes mellitus associated with pituitary gigantism. Pituitary 10: 359-364. [Crossref]

19. Waterhouse M, Sabin I, Plowman N, Akker S, Chowdhury TA (2009) A "growing cause" of diabetic ketoacidosis. BMJ Case Rep 2009. [Crossref]

20. Carrasco de la Fuente M, González-Albarrán O, Pérez López G, Cano Megías M (2010) Diabetic ketoacidosis as the first manifestation of a mixed growth hormone and prolactin-secreting tumor. Endocrinol Nutr 57: 507-509.

21. Mewawalla P, Jaiswal G, Moustakakis M, Sankaranarayanan N, Dasanu CA (2011) Refractory DKA as first presentation of acromegaly and a potential role for continuous venovenous hemofiltration in its successful management. Conn Med 75: 405-407.

22. Palakawong P, Arakaki R (2012) Diabetic Ketoacidosis in Acromegaly: A Case Report. Endocr Pract 2012; 27:1-15. [Crossref]

23. Yoshida N, Goto H, Suzuki H, Nagasawa K, Takeshita A, et al. (2013) Ketoacidosis as the initial clinical condition in nine patients with acromegaly: a review of 860 cases at a single institute. Eur J Endocrinol 169: 127-132.

24. Dosi RV, Patell RD, Shah PJ, Joshi HK (2013) Diabetic ketoacidosis: an unusual presentation of acromegaly. BMJ Case Rep 2013. [Crossref]

Copyright: $@ 2017$ Kabadi UM. This is an open-access article distributed under the terms of the Creative Commons Attribution License, which permits unrestricted use, distribution, and reproduction in any medium, provided the original author and source are credited. 